\title{
Soil organic carbon dynamics of black locust plantations in the middle Loess Plateau area of China
}

\author{
N. Lu' ${ }^{1}$, J. Liski ${ }^{2}$, R. Y. Chang ${ }^{3}$, A. Akujärvi ${ }^{2}$, X. Wu ${ }^{1}$, T. T. Jin ${ }^{4}$, Y. F. Wang ${ }^{1}$, and B. J. Fu ${ }^{1}$ \\ ${ }^{1}$ State Key Laboratory of Urban and Regional Ecology, Research Center for Eco-Environmental Sciences, \\ Chinese Academy of Sciences, Beijing, 100085, China \\ ${ }^{2}$ Finnish Environment Institute (SYKE), Natural Environment Centre/Ecosystem Change Unit, Helsinki, Finland \\ ${ }^{3}$ Institute of Mountain Hazards and Environment, Chinese Academy of Sciences, Chengdu, 610041, China \\ ${ }^{4}$ China Institute of Water Resources and Hydropower Research, Beijing, 100038, China
}

Correspondence to: B. J. Fu (bfu@ rcees.ac.cn)

Received: 17 June 2013 - Published in Biogeosciences Discuss.: 8 July 2013

Revised: 25 September 2013 - Accepted: 29 September - Published: 7 November 2013

\begin{abstract}
Soil organic carbon (SOC) is the largest terrestrial carbon pool and sensitive to land use and cover change; its dynamics are critical for carbon cycling in terrestrial ecosystems and the atmosphere. In this study, we combined a modeling approach and field measurements to examine the temporal dynamics of SOC following afforestation (Robinia pseudoacacia) of former arable land at six sites under different climatic conditions in the Loess Plateau during 19802010, where the annual mean precipitation ranging from $450 \mathrm{~mm}$ to $600 \mathrm{~mm}$. The results showed that the measured mean SOC increased to levels higher than before afforestation when taking the last measurements (i.e., at age 25 to $30 \mathrm{yr}$ ) at all the sites, although it decreased at the wetter sites in the first few years. The accumulation rates of SOC were 1.58 to $6.22 \% \mathrm{yr}^{-1}$ in the upper $20 \mathrm{~cm}$ and 1.62 to $5.15 \% \mathrm{yr}^{-1}$ in the upper $40 \mathrm{~cm}$ of soil. The simulations reproduced the basic characteristics of measured SOC dynamics, suggesting that litter input and climatic factors (temperature and precipitation) were the major causes for SOC dynamics and the differences among the sites. They explained 88-96, 48-86 and 57-74\% of the variations in annual SOC changes at the soil depths of 0-20, 0-40, and 0-100 cm, respectively. Notably, the simulated SOC decreased during the first few years at all the sites, although the magnitudes of decreases were smaller at the drier sites. This suggested that the modeling may be advantageous in capturing SOC changes at finer timescale. The discrepancy between the simulation and measurement was a result of uncertainties in model structure, data input, and sampling design. Our findings indicated that
\end{abstract}

afforestation promoted soil carbon sequestration at the study sites during 1980-2010. Afforestation activities should decrease soil disturbances to reduce carbon release in the early stage. The long-term strategy for carbon fixation capability of the plantations should also consider the climate and site conditions, species adaptability, and successional stage of recovery.

\section{Introduction}

Soil organic carbon (SOC) is the largest terrestrial carbon pool. A slight change in SOC may greatly influence ecosystem carbon cycling and atmosphere $\mathrm{CO}_{2}$ concentration (Davidson and Janssens, 2006). SOC stock is sensitive to land use and cover change (Guo and Gifford, 2002; Wiesmeier et al., 2012), which alter both carbon inputs (amount and quality of litter mass) and losses (decomposition and mineralization).

In recent decades, human disturbances, such as deforestation, urbanization and afforestation, have caused extensive changes in land use and cover globally. The large-scale changes in terrestrial ecosystems have caused great concern about the temporal dynamics of energy and mass flows during ecosystem succession or recovery (Breña Naranjo et al., 2011). To date, soil carbon dynamics following disturbances have not been well documented, especially for the later phases of succession (Foote and Grogan, 2010). 


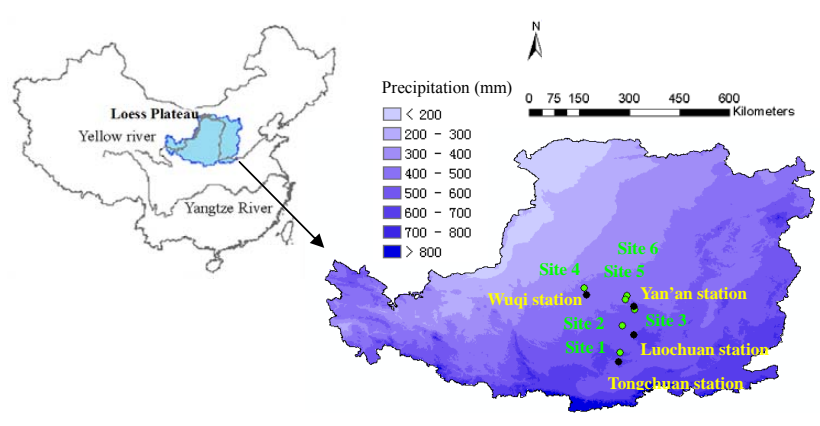

Fig. 1. Location of the six sites in this study and the adjacent longterm meteorological stations in the Loess Plateau, China.

The Loess Plateau is the largest continuous area of loess in the world (about $70 \%$ of global loess distribution) covering an area of $640000 \mathrm{~km}^{2}$. It was well-known for its severe soil erosion caused by long-term cultivation and destruction of natural vegetation in its long history (Fu, 1989; Shi and Shao, 2000). Since the 1970s, a series of ecological restoration projects have been implemented in the Loess Plateau, such as the soil-water conservation projects and the Grain for Green (GfG) project. Soil erosion has decreased significantly after the implementation of these ecological restoration projects (Fu et al., 2011). Currently, the main ecological problems in this area have turned from erosion control to ecosystem recovery and coordination between water and vegetation development, especially in the dry areas. Accurate estimates of carbon sequestration and prediction of their future carbon fixation capacity (mitigation potential to climate change) are among the most important aspects for evaluation of the ecological and social effects of these restoration projects.

Stand age and climate are two important factors closely related to the changes in soil carbon stock of forest ecosystem (Peltoniemi et al., 2004). Soil carbon estimates may lead to a large bias if stand age is considered as a static variable. However, in-depth understanding of the temporal changes of SOC and its controlling mechanisms with stand age is still lacking (Adams et al., 2011). In the Loess Plateau, many studies have quantified and evaluated SOC stock and the variation caused by land use and cover change (Fu et al., 2010; Han et al., 2010; Liu et al., 2012), but most of them focused on comparing SOC differences among various land use types or its static spatial heterogeneity. In addition, since the area of the Loess Plateau ranges over a precipitation gradient of 200-800 mm (Fig. 1), the trans-regional comparison of soil carbon dynamics in different climate conditions also needs further investigation for the wide range of afforestation at the regional scale.

Typical methods for estimating soil carbon dynamics include repeated field surveys, paired sites, chronosequence (or "space for time substitution"), and modeling. SOC estimate from direct measurement is most accurate but usually suf- fers from long time interval of repetition (e.g., 5-10 yr) due to limitations of time and labor. Chronosequence is advantageous for getting the measurements of varied stand ages in a relatively short time, but it is often difficult to find continuous series of stand ages in reality, and therefore a chronosequence can provide only a few points of time for the temporal sequences (Mäkipää et al., 2012). Modeling is an effective alternative or complement to repeated field surveys in studying soil carbon change following disturbance (FAO (Food and Agriculture Organization) report 2004; Oelbermann and Voroney, 2011), but model parameterization and validation are indispensable of field measurements.

In this study, we estimated the SOC stock and changes following afforestation in the Loess Plateau by using the Yasso07 model integrated with chronosequence field investigations. The central aim of this study was to examine the temporal dynamics of SOC and factors controlling these dynamics after afforestation at site scale during 1980-2010. The specific objectives were to (1) quantify SOC stock and changes following afforestation at six sites with different climatic conditions, (2) examine the factors and processes that affected SOC dynamics and their differences among sites, and (3) evaluate the performance of the Yasso07 model application in the Loess Plateau.

\section{Materials and methods}

\subsection{Study sites}

The six study sites are located in the Shaanxi province, which is in the central to southern part of the Loess Plateau (Fig. 1). The soil types are loessial soils with low SOC and clay content and high water permeability. The annual mean temperature $(T)$ ranges from 8.1 to $10.6^{\circ} \mathrm{C}$ for the six sites. The annual precipitation $(P)$ is around $600 \mathrm{~mm}$ at sites 1 and 2 (wetter sites in this study) and $450-500 \mathrm{~mm}$ at sites 3, 4, 5 and 6 (drier sites in this study) (Fig. 2). More detailed site information is summarized in Table 1.

\subsection{Sampling}

The field measurements were taken in July 2009 or 2010 by using the chronosequence approach. At each of the six sites, a series of plots of different-aged black locust (Robinia pseudoacacia) plantations, which was the main plantation type in this region, were selected for vegetation and soil investigations (Table 1). We tried to select separated age classes and keep minimum differences in stand characteristics, including slope position (upper position) and degree (slight grade). The plot area was $20 \mathrm{~m} \times 20 \mathrm{~m}$. In each plot, the diameter at breast height $(\mathrm{DBH})$, the number of trees, and the average tree height were measured (Table S1). Subplot $1 \mathrm{~m}$ from the trunk of the standard trees (four trees in one plot) and one or two subplots $(1 \mathrm{~m} \times 1 \mathrm{~m})$ in the forest gap(s) were established, respectively. In each subplot, the soil samples 
Table 1. Description of site characteristics: $P$ - annual precipitation, $T$ - annual mean temperature, PET - potential evapotranspiration, Amplitude - inter-annual temperature change, $\mathrm{C}: \mathrm{N}$ ratio of soil total carbon to nitrogen. Soil property parameters are for soil depths $0-$ $20 \mathrm{~cm}$.

\begin{tabular}{|c|c|c|c|c|c|c|c|c|c|}
\hline $\begin{array}{l}\text { Site } \\
\text { ID* }^{*}\end{array}$ & $\begin{array}{l}\text { Name of the } \\
\text { closest } \\
\text { met-station }\end{array}$ & $\begin{array}{r}P \\
(\mathrm{~mm})\end{array}$ & $\begin{array}{r}T \\
\left({ }^{\circ} \mathrm{C}\right)\end{array}$ & $P / \mathrm{PET}$ & $\begin{array}{r}\text { Amplitude } \\
\left({ }^{\circ} \mathrm{C}\right)\end{array}$ & $\begin{array}{r}\text { Bulk } \\
\text { density } \\
\left(\mathrm{g} \mathrm{cm}^{3}\right)\end{array}$ & $\begin{array}{r}\text { Clay } \\
\text { content } \\
(\%)\end{array}$ & $\begin{array}{l}\text { Soil } \\
\mathrm{C}: \mathrm{N} \\
\text { ratio }\end{array}$ & $\begin{array}{r}\text { No. } \\
\text { of } \\
\text { plots }\end{array}$ \\
\hline 1 & Tongchuan & 604 & 9.8 & 0.62 & 13.3 & 1.14 & 27.1 & 27.7 & 8 \\
\hline 2 & Luochuan & 598 & 10.6 & 0.63 & 13.2 & 1.20 & 34.9 & 13.5 & 7 \\
\hline 3 & Yan'an & 519 & 10.2 & 0.52 & 14.4 & 1.17 & 16.1 & 36.4 & 8 \\
\hline 4 & Wuqi & 454 & 8.1 & 0.51 & 14.7 & 1.22 & 19.3 & 37.2 & 4 \\
\hline 5 & Yan'an & 519 & 10.2 & 0.52 & 14.4 & 1.08 & n.a. & n.a. & 6 \\
\hline 6 & Yan'an & 519 & 10.2 & 0.52 & 14.4 & 1.19 & n.a. & n.a. & 4 \\
\hline
\end{tabular}

* Land use history of the six study sites: for site 1 and 2, secondary forest developed on a fallow field abandoned in the 1860 s due to emigration (Zou et al., 2002); the land was reclaimed in the 1950s and afforested in the 1980s. For site 3, 4, 5, and 6, the land had been cultivated for hundreds to thousands of years before afforestation in the 1970s.
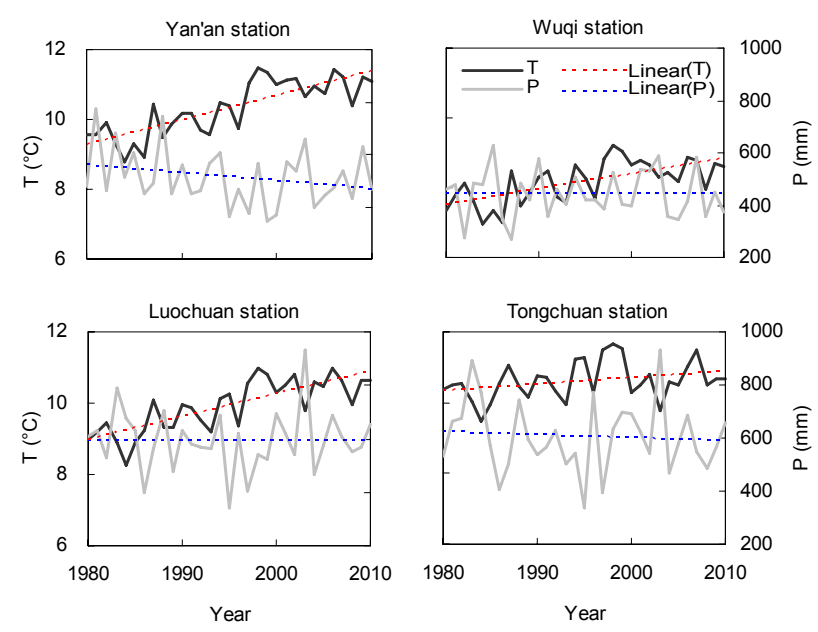

Fig. 2. The variations of annual mean temperature $(T)$ and precipitation $(P)$ at the four meteorological stations from 1980 to 2010. The dotted lines are linear trends for $T$ in red and $P$ in blue, respectively. The trends are all significant for $T$ except for the Tongchuan station and insignificant for $P$ for all the stations $(p<0.05)$.

were taken from the mineral soil layers at the intervals $0-5$, $5-10,10-20,20-30,30-40,40-60,60-80$, and $80-100 \mathrm{~cm}$ along the soil vertical profile using cylindrical cores, with four replicates for each soil layer (Chang et al., 2012a, b). The biomass of forest floor vegetation was harvested for each subplot.

At each site, a cropland plot adjacent to the plantation plots (dozens to hundreds of meters) was established. The soil samples were taken at the same depth intervals as in the plantation plots with four to five replicates for each depth. The species of the croplands were wheat, soybean and millet, and had been planted in recent decades using the annual rotation method.

\subsection{Soil analysis}

The fraction of SOC $\left(\mathrm{SOC}_{i}\right)$ in a given soil depth was estimated by the potassium-dichromate oxidation method. The total amount of SOC $\left(\mathrm{MgCha}^{-1}\right)$ above a given soil depth (i.e., 20,40, and $100 \mathrm{~cm}$ in our analyses) was estimated as sum of the products of $\mathrm{SOC}_{i}$, bulk density $\left(\mathrm{g} \mathrm{cm}^{-3}\right)$ and different soil intervals above that depth. The fine roots $(<2 \mathrm{~mm}$ in diameter) were extracted from the soil samples by washing. The biomass of fine root and forest floor vegetation was weighed after dried at $65^{\circ} \mathrm{C}$ to constant. Bulk density was estimated as the ratio of dry soil mass at $105^{\circ} \mathrm{C}$ to the volume of cylindrical core. Soil texture was estimated with the laser particle size analyzer (Mastersizer 2000, Marlven, Ltd. UK). Total soil carbon (TC) and total nitrogen (TN) were analyzed by the dry combustion method with a Vario EL Element Analyzer.

\subsection{Model structure}

Yasso07 is a dynamic soil carbon model developed from its earlier version, Yasso (Liski et al., 2005). The model consists of five decomposition components and two litter components of woody and non-woody litters (Fig. 3). It is assumed that (1) litters consist of four compound groups, including soluble in ethanol (E) or water (W), hydrolyzable in acid (A), and neither soluble nor hydrolyzable (N); (2) decomposition rate of the non-woody litter is determined by climate and the carbon fractions (EWAN); (3) decomposition of woody litter is determined by climate, EWAN composition as well as its physical size; and (4) decomposition of the EWAN groups results in mass loss from the system, mass flows between the groups, and formation of more stable humus (Karhu et al., 2011; Tuomi et al., 2011). The model input includes litter input (quantity and chemical quality of litter), climate ( $P$, $T$ and temperature amplitude), and standard deviations (SD) of each variable. The model output includes SOC stock and change as well as the probability densities. Information about 


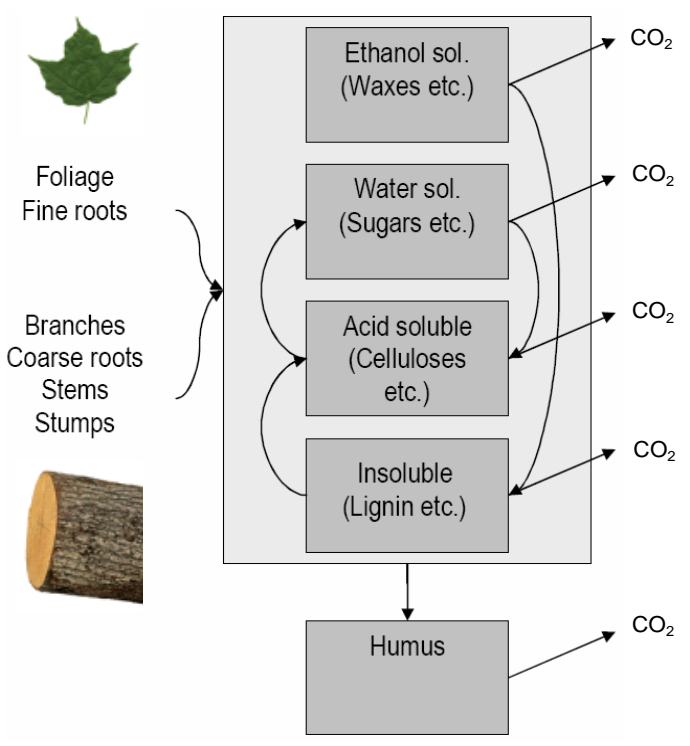

Fig. 3. Flow chart of Yasso07 model. The boxes represent carbon compartments and the arrows are carbon fluxes among compartments, into (litter input to the soil) or out of compartments $\left(\mathrm{CO}_{2}\right.$ release by decomposition).

the model parameterization and main equations can be found in the literature (Peltoniemi et al., 2007; Karhu et al., 2011; Thum et al., 2011).

\subsection{Model input data}

We chose four nearest stations for climate input to the model (Fig. 1, Table 1). The initial litter input of each site was estimated based on the annual crop yield (4000-5000 $\mathrm{kg} \mathrm{ha}^{-1}$ ), harvest index and crop water content (Fang et al., 2007). It was assumed that the SOC level of the plantation in the beginning of afforestation was the same as the corresponding cropland at each site. The annual carbon inputs were estimated based on biomass estimation and turnover rates. Biomass of stem, bark, branch, leaf, and coarse roots were estimated individually using specific empirical models with DBH (Tian et al., 1997). The biomass of fine root and forest floor vegetation were directly measured from the field samples. The estimated and measured biomass components were converted to carbon mass by multiplying by 0.5 and extrapolated to stand scale by area conversion and multiplying by the stand tree density. Due to the discontinuous age sequence of the plantations and the missing data for fine root biomass at some plots, we assumed that the litter biomass of each component and the total litter biomass changed linearly from 1980 to 2010 (Figs. 4 and 5). Thus, the annual litter biomass was estimated based on the linear regression equation for each site. The changes of total biomass input to different soil layers were dependent on the changes of fine root biomass.
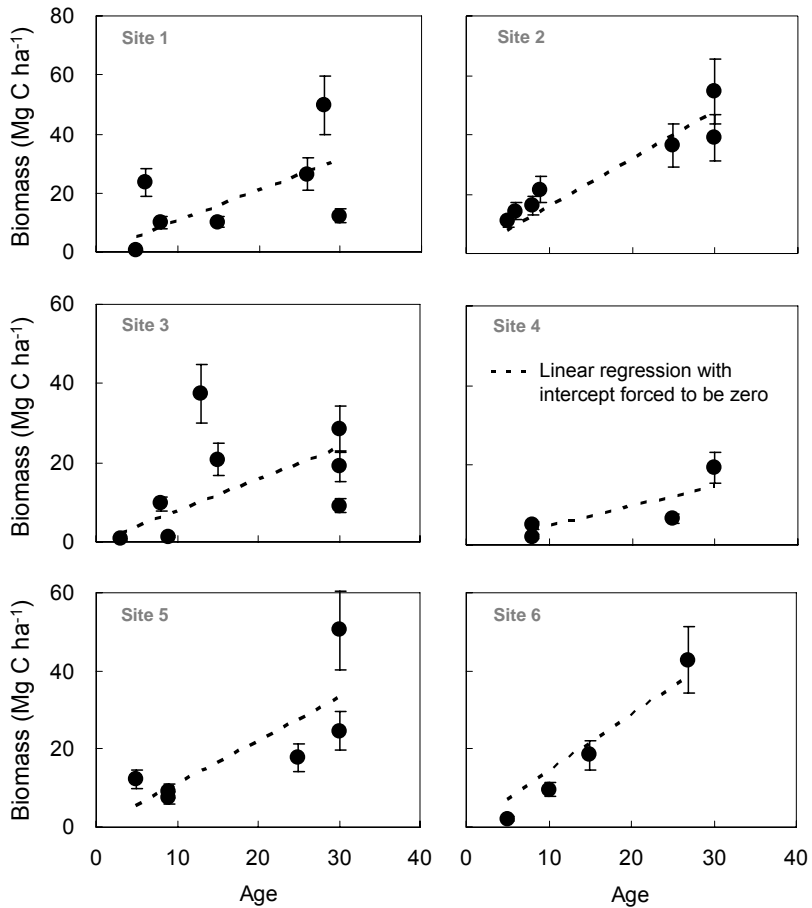

Fig. 4. The changes of total carbon biomass of the plantations with stand age (including floor vegetation but excluding fine root) at the six sites. Error bars are standard deviations.
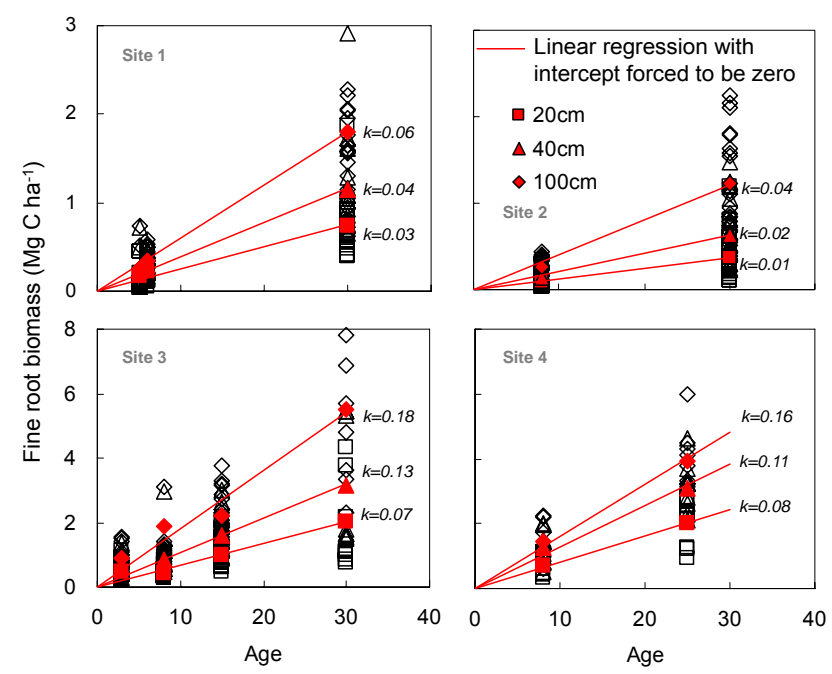

Fig. 5. The changes of mean fine roots carbon biomass with plantation age at different soil depths. The black symbols are samples and the red symbols are means. $k$ is the regression slope. The coefficients of determination of the linear regressions are $R^{2} \geq 0.96$ at $p<0.05$. Figures are not shown for sites 5 and 6 due to missing data. 

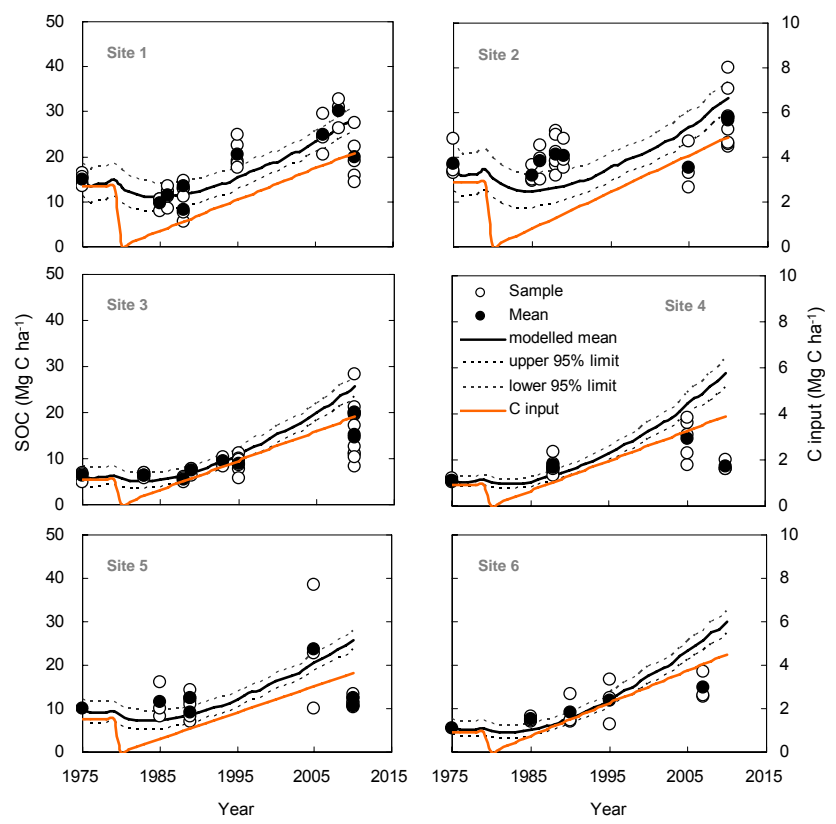

Fig. 6. Comparison of simulated and measured SOC stock in the 0 $20 \mathrm{~cm}$ soil depths following afforestation. The first $y$ axis represents SOC stock. The second $y$ axis represents litter carbon biomass.

\subsection{Model simulations}

The model was operated for the soil depths $0-20 \mathrm{~cm}, 0$ $40 \mathrm{~cm}$, and $0-100 \mathrm{~cm}$ from 1975 to 2010 on an annual basis. In the model simulations, woody litter and non-woody litter were summed and used as input to the mode as two data lines for each time step. When initializing the model, we assumed that the SOC was at steady state with the litter inputs from the crops. The model was run for five years before afforestation (i.e., 1975-1980), during which time the litter inputs were adjusted to make the simulated SOC equal to the measured SOC values of the croplands.

The SD values of turnover rates for each litter type were obtained by the Monte Carlo method. Since the turnover rate was highly varied and uncertain, we set the low and high values to be 0.5 and 1.5 times the average values, respectively (Zhai et al., 2002; Peltoniemi et al., 2004; Liski et al., 2006). The SD values for other litter components estimated using the DBH-biomass functions were obtained by multiplying the estimated litter mass by the coefficients of variation (0.2). The values of EWAN fractions were taken or calculated based on the literature (Adamopoulos et al., 2005; Jensen et al., 2005; Wang et al., 2011).

\subsection{Statistical analysis}

ANOVA and repeated measures ANOVA analyses were conducted to test the differences in the initial SOC stocks and SOC changes since afforestation among sites, respectively. To predict the annual litter production based on the biomass
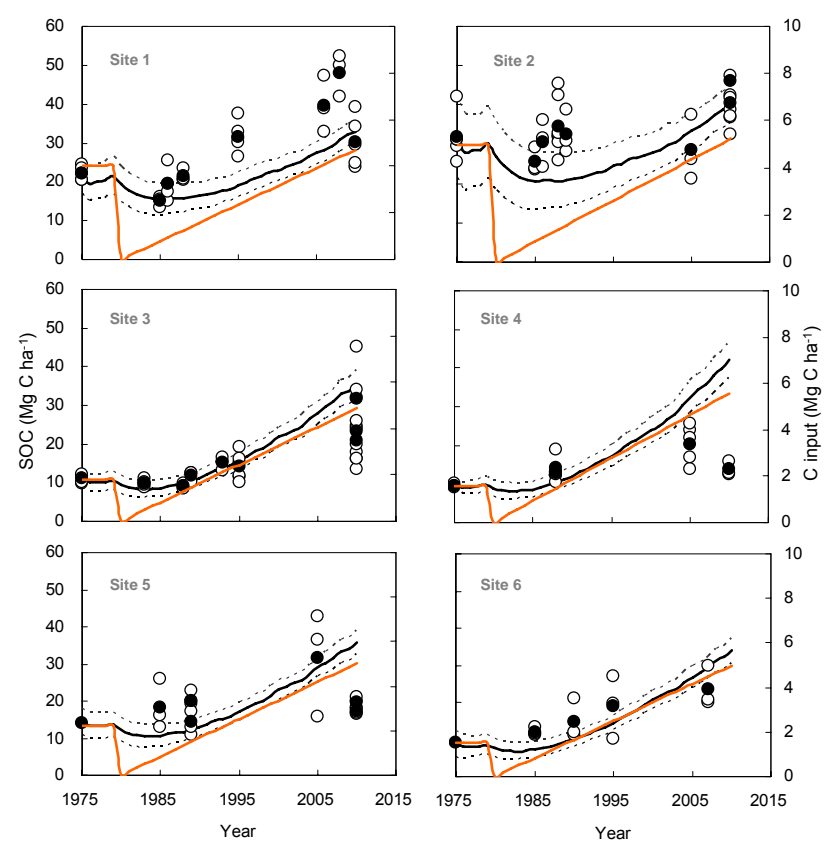

Fig. 7. Comparison of simulated and measured SOC stock in the $0-40 \mathrm{~cm}$ soil depths following afforestation. All other designations are the same as those in Fig. 6.

estimations of the measured discontinuous-aged plantation plots, the linear regression analysis was conducted to estimate the annual biomass at each site. The general linear model (GLM) was used to examine the effects of climate factors and litter input in explaining the interannual dynamics of SOC changes after afforestation. Additionally, the Pearson correlation analysis was used to test the correlations between the model residuals and soil property parameters and plantation age to reveal the potential systematic deficiencies of the model. The statistical analyses were conducted using the Statistical Analysis System, version 9 (SAS 9.0).

\section{Results}

\subsection{Measured SOC stock and dynamics}

The initial SOC stocks were significantly higher at the wetter $(1$ and 2$)$ than the drier $(3,4,5$, and 6$)$ sites $(p<0.01)$ (Figs. 6-8). The means of the $0-20,0-40$, and $0-100 \mathrm{~cm}$ soil layers were respectively $16.7,27.0$, and $38.3 \mathrm{MgCha}^{-1}$ at the wetter sites, and $6.8,10.9$, and $16.1 \mathrm{MgCha}^{-1}$ at the drier sites. This may partly have resulted from the differences in both the climate and the land use history between the wetter and drier sites (Table 1).

After afforestation, the SOC stocks were also significantly higher at the wetter than the drier sites in each of the three soil layers $(p<0.01)$ (Figs. 6-8). The stock was a little smaller at site 1 than site $2(p<0.05)$, but there were no 

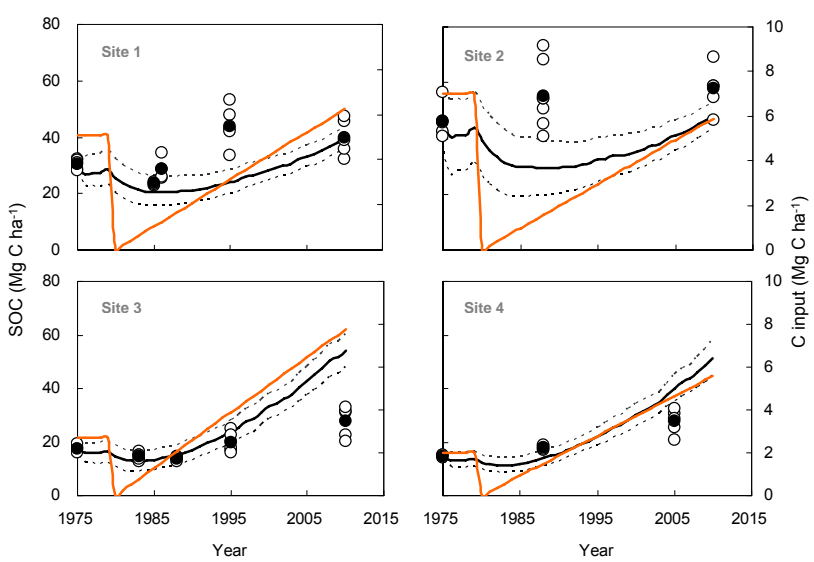

Fig. 8. Comparison of simulated and measured SOC stock in the $0-100 \mathrm{~cm}$ soil depths following afforestation. Figures are not shown for sites 5 and 6 due to missing SOC data for $60-100 \mathrm{~cm}$ soil depths. All other designations are the same as those in Fig. 6.

significant differences between the drier sites $3,4,5$, and $6(p>0.05)$. The variance estimates of the site-time interaction indicated that the changes in SOC were site specific over time $(p<0.002)$.

The measured mean SOC decreased at the wetter sites and remained more or less the same at the drier sites during the first few years after afforestation (Figs. 6-8). Thereafter, SOC increased gradually except for the drop-off points at sites 4 and 5 at the age of $30 \mathrm{yr}$. The SOC stock was higher than before afforestation at each site at the time of taking the last measurements.

According to the linear trends fitted to the measurements from 1980 to 2010, the overall rate of SOC accumulation was $0.54,0.30,0.39,0.21,0.16$, and $0.29 \mathrm{MgC} \mathrm{ha}^{-1} \mathrm{yr}^{-1}$ in the $0-20 \mathrm{~cm}$ soil layer of sites 1 to 6 , respectively. In the $0-40 \mathrm{~cm}$ soil layer, it was $0.79,0.36,0.57,0.17,0.23$, and $0.55 \mathrm{MgC} \mathrm{ha}^{-1} \mathrm{yr}^{-1}$. The relative rates of carbon accumulation (i.e., linear trend divided by the initial value, $\triangle \mathrm{SOC} \%$ ) were $1.58-6.22 \% \mathrm{yr}^{-1}$ in the $0-20 \mathrm{~cm}$ soil layer and 1.62 $5.15 \% \mathrm{yr}^{-1}$ in the $0-40 \mathrm{~cm}$ layer. The relative rates were higher at the drier than the wetter sites. The rate for $0-100 \mathrm{~cm}$ was not calculated because of too few samples.

\subsection{Modeled SOC stock and dynamics}

The simulations produced the same basic characteristics of SOC dynamics as the measurements. Notably, the simulated SOC decreased during the first few years after afforestation at all the sites, although the magnitude of the decreases were smaller at the drier sites (Figs. 6-8). The SOC reached its minimum value 3 to $8 \mathrm{yr}$ after afforestation. After this, it recovered to the original levels and increased until the end of the simulations. The soils were thus releasing carbon for the first 3 to $8 \mathrm{yr}$ after afforestation and gaining carbon thereafter (Fig. 9). The soils of the wetter sites lost more carbon and re-

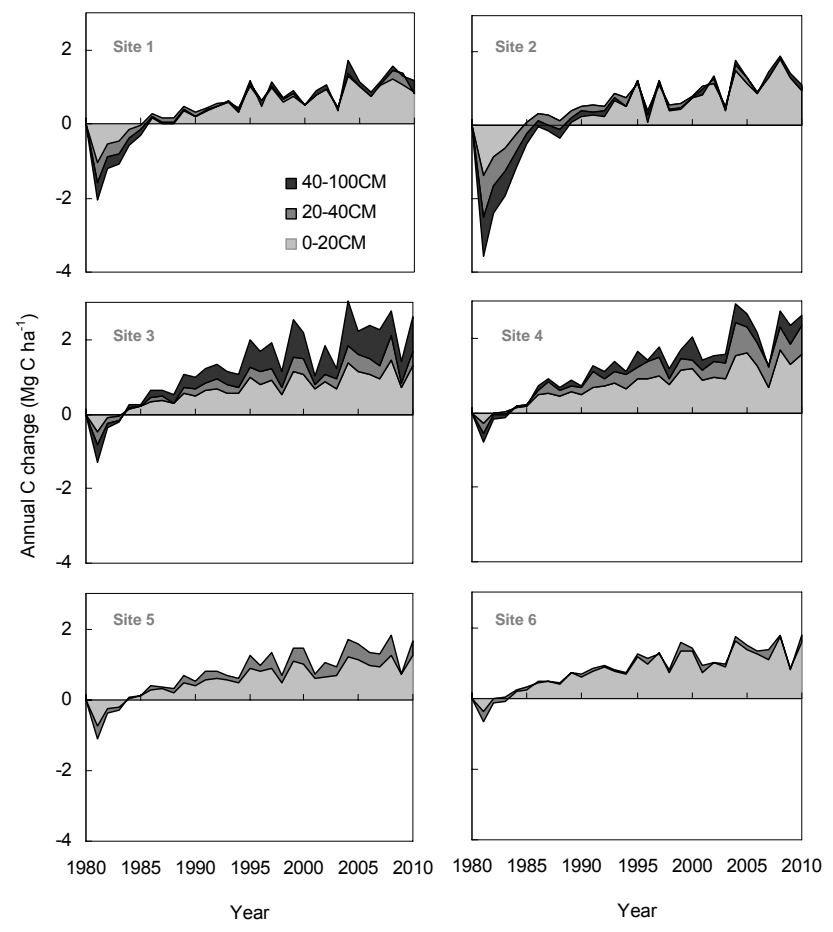

Fig. 9. Simulated annual SOC change over time since afforestation at the six study sites.

mained as carbon sources for a longer time after afforestation than the soils of the drier sites.

In addition to these basic patterns, the simulated changes in SOC were highly variable from year to year (Fig. 9). The annual mean $T$ and annual $P$ accounted for 26-67\%, 19$65 \%, 16-57 \%$ variances $(p<0.05)$ of annual SOC changes in the $0-20 \mathrm{~cm}, 20-40 \mathrm{~cm}$, and $40-100 \mathrm{~cm}$ soil depths at the six sites, respectively. By including annual $T, P$, and litter inputs, the efficiency of the GLM models was improved, explaining $88-96,48-86$ and $57-74 \%$ of variations $(p<0.002)$ in annual SOC changes for 0-20, 20-40 and 40-100 cm soil depths for the six sites, respectively, noting that annual litter input was correlated with climate variability. The variations of SOC changes were more accounted for by litter input and climate in the upper soil depths, suggesting that some other factors may affect the SOC dynamics in deeper soil depths. In addition, different soil depths have varied contributions to the annual SOC changes in the $0-100 \mathrm{~cm}$ soil depths at all of the six sites, where SOC changes in the $0-20 \mathrm{~cm}$ soil depths were the major causes (Fig. 9).

\subsection{The model performance}

The modeled SOC stocks agreed generally well with the measurements of the different soil layers and study sites. The measured SOC means fell mostly within the upper and lower $95 \%$ confidence levels (Figs. 6-8). The model tended to underestimate the SOC stock at early ages for the wetter sites 

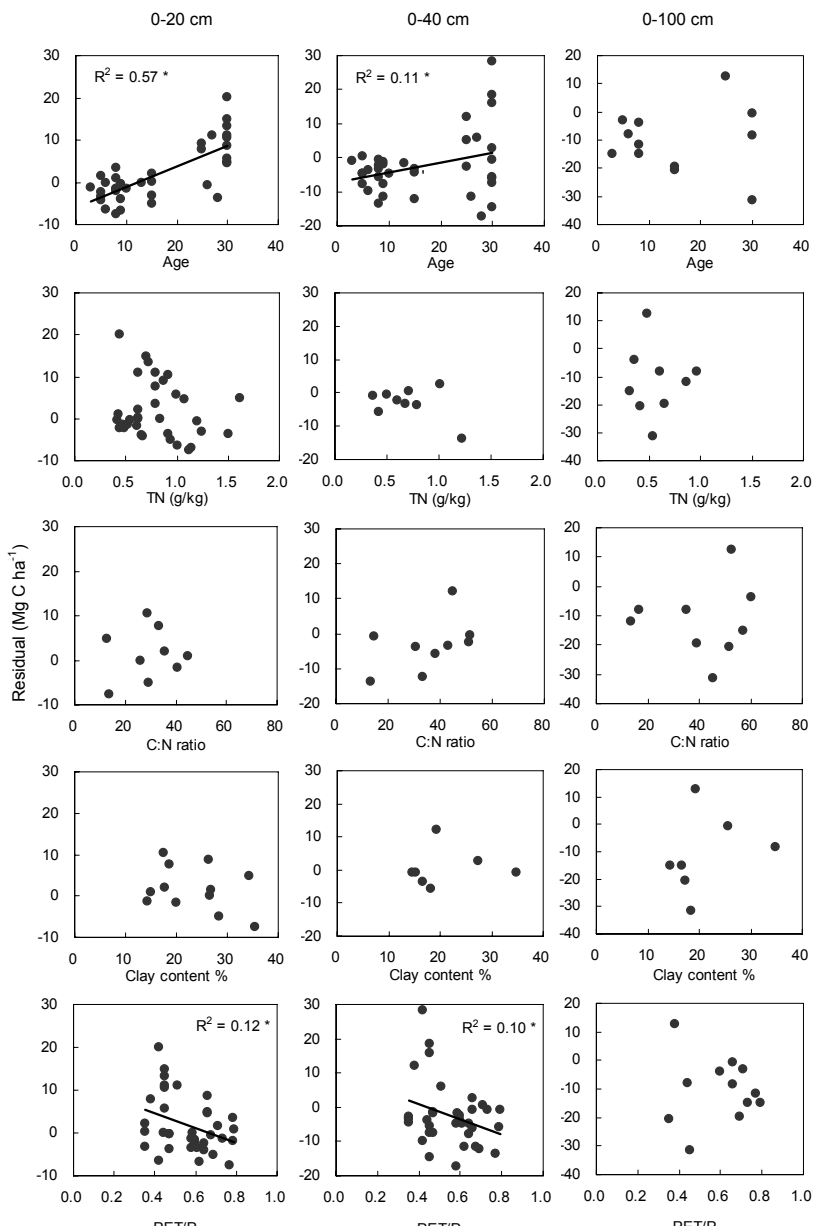

PET/P

Fig. 10. Correlations of model residuals (modeled-measured mean) with plantation age, soil $\mathrm{TN}$, soil $\mathrm{C}: \mathrm{N}$ ratio, clay content, and $\mathrm{PET} / P$ in three soil depth ranges. Star indicates the correlation is significant $(p<0.05)$.

and overestimate the SOC stock at late ages for the drier sites. The model residuals (modeled-measured means) of 0-20 and $0-40 \mathrm{~cm}$ soil layers over the six sites increased with plantation age, suggesting that the model overall overestimated the SOC stocks at older ages (Fig. 10). These discrepancies between the modeled and measured SOC indicate that there are deficiencies or uncertainties in the methods and/or measurements.

The results of the residual analyses showed that the residuals had no significant correlations with $\mathrm{TN}, \mathrm{C}: \mathrm{N}$ ratio or clay content. However, the residuals were negatively correlated with $P$ / PET ratios (an index of soil moisture) and these trends were statistically significant in the $0-20$ and $0-40 \mathrm{~cm}$ soil layers (Fig. 10), suggesting that the modeling approach tended to underestimate SOC in wetter soil water conditions.

\section{Discussion}

\subsection{Soil carbon dynamics following afforestation}

This study estimated the SOC stocks and changes following black locust afforestation of former arable lands at six sites in the Loess Plateau. The results showed that the SOC generally decreased in the first few years, recovered to the original levels and then continued to increase, furthering growth of the plantation during 1980-2010. The time of source-to-sink transition (3-8 yr) and SOC recovery (10-15 yr) were comparable to other studies of SOC dynamics after afforestation (Paul et al., 2002; Peoplau et al., 2011; Li et al., 2012).

A decrease of SOC in the first few years following afforestation has been frequently observed and attributed to decreased litter inputs and increased decomposition rates compared to those prior to afforestation (Paul et al., 2002; Laganiere, Angers and Pare, 2010; Karhu et al., 2011). In some studies where the initial soil carbon stock was very low (2$3 \mathrm{~kg} \mathrm{C} \mathrm{m}^{-2}$ at $0-10 \mathrm{~cm}$ soil depths), SOC was found to linearly increase with time after afforestation (Foote and Grogan, 2010). In our study, the decreases of SOC in the first few years after afforestation were not detected and could be linearly fitted with time based on the field measurements at the drier sites. This may be related to the low initial SOC stocks of the croplands at the drier sites $\left(\sim 1.6 \mathrm{~kg} \mathrm{C} \mathrm{m}^{-2}\right.$ at $0-20 \mathrm{~cm}$ ). It is also possible that the detailed changes of SOC were concealed by the relatively large age observation intervals between the plantations. In this aspect, the modeling may be advantageous in capturing small SOC changes at finer temporal scale.

The larger SOC decreases at the wetter than the drier sites in the first a few years may be because the larger initial SOC stock and higher soil water availability caused more intensive biotic activities and higher soil carbon decomposition rates under disturbances at the wetter sites (Jandl et al., 2007), such as land preparation and planting. This indicated that decrease of soil disturbance could help to reduce carbon release in afforestation. Nevertheless, the vegetation has accumulated carbon on average 10.75 at the wetter sites and $8.56 \mathrm{MgCha}^{-1}$ at the drier sites at age of $8 \mathrm{yr}$, which compensated the losses of carbon from the soils (4.59 and $3.03 \mathrm{MgC} \mathrm{ha}^{-1}$ in the upper $40 \mathrm{~cm}$ ).

\subsection{Rate of SOC change}

Land use conversions from cropland to tree plantations are generally regarded as the most efficient aggrading systems for soil carbon sequestration (Stockman et al., 2011), although there are also findings of negative or no effects (Davis et al., 2007; Laganiere et al., 2010; Wiesmeier et al., 2012). These contrasting findings may be related to different climates, timescales (i.e., year after afforestation), site disturbances, and/or initial SOC stock among the studies (Smal and Olszewska, 2008). In this study, the measured relative 
rates of carbon accumulation during the study period (i.e., $30 \mathrm{yr}$ ) ranged from 1.58 to $6.22 \% \mathrm{yr}^{-1}$ in the upper $20 \mathrm{~cm}$, and 1.62 to $5.15 \% \mathrm{yr}^{-1}$ in the upper $40 \mathrm{~cm}$ of soil. These values are higher on average than the findings of a meta-study of $1.22 \pm 1 \% \mathrm{yr}^{-1}$ at soil depths of $30 \pm 6 \mathrm{~cm}$ for croplandconverted plantations in the first $20 \mathrm{yr}$ (Peoplau et al., 2011). Our results suggest that black locust is relatively efficient in soil carbon sequestration in our study region, which could be partly explained by the $\mathrm{N}$ fixation ability of the mycorrhizae in its roots (Geesing et al., 2000).

High precipitation and soil clay content are usually favorable for soil carbon accumulation (Laganiere et al., 2010). Our results do not support this conclusion as the relative accumulation rates $(\triangle \mathrm{SOC} \%)$ were a little lower at the wetter than the drier sites. This may be partly caused by the relatively lower rates of fine root litter input to the soil at the wetter sites (Fig. 5). The relationships between fine root biomass, water availability and fertility were not consistent among species and sites as both positive and negative relations have been reported (Chang et al., 2012b). The negative relationship we found here could be a strategy of the species to adapt to the environment. That is to say, the trees tried to get access to more water and nutrients by growing more fine roots at the drier sites. The effects of fine root dynamics on the changes of SOC needs further studies in the future as it is a critical contributor to total litter input of soil.

\subsection{Interannual variability in soil carbon change}

The annual changes of SOC showed high interannual variability in addition to the general increasing trends following afforestation. This variability has not been examined in our study region because the annual estimates of SOC have not been obtained from previous field inventories. The plantations were free from human activities at our study sites during 1980-2010; therefore, the SOC dynamics were mainly affected by the variability in climate, litter productions of the plantations as well as their interactions $(87.18-96.0 \%$ in 0 $20 \mathrm{~cm}$ ), wherein annual $T$ and $P$ contributed $25.7-66.6 \%$. It is worthy to note that the climate regulates the annual variability of litter productivity and decomposition simultaneously. The interactions between climatic factors and litter could contribute large fractions of variability in annual SOC changes. Warmer temperature and higher precipitation can increase biomass production and decomposition rate at the same time. The trend of carbon accumulation in the soil results from all of the combined factors, such as the general increasing trend of litter production and the changing climate in the study period (Figs. 2, 4, 5). In addition, the weaker explanation of annual SOC changes by climate and litter in deeper soil depths indicates that some other processes may affect the SOC dynamics, e.g. the redistribution of SOC along the soil profile by eluviation due to intense rainfall in summertime and high water permeability of the loess soil in the study region.

\subsection{Model performance}

The simulations reproduced the basic characteristics of SOC dynamics as the measurement. This suggested that the quantity and quality of litter input to the soil and the climatic factors accounted for in the simulations were major causes for the temporal changes in SOC after afforestation and the differences among the sites. Some studies have found that soil $\mathrm{N}$ and clay content can greatly influence SOC alteration after land use change (Chapin et al., 2009). However, we did not find significant correlations between soil $\mathrm{N}$ or clay content and the model residuals. This may be because black locust is a $\mathrm{N}$-fixing species and $\mathrm{N}$ was not the primary limiting factor to soil carbon sequestration in our study region. Soil clay content may be important for SOC stabilization at the century timescale (Torn et al., 1997; Karhu et al., 2011), but its effect could be negligible in a shorter time period.

Soil water availability is another factor that influences soil carbon stabilization but not included in Yasso07. Although precipitation was included in the model, the model sensitivities may not follow the same patterns when changed by precipitation and soil water (Rantakari et al., 2012). As indicated by Häkkinen et al. (2011), the sensitivity of predicted SOC annual changes by Yasso07 may be too high in response to precipitation. Also, the effects of soil moisture on SOC dynamics remain large uncertainties in the model (Rantakari et al., 2012). Soil water decrease following afforestation has been widely reported in the Loess Plateau due to high evapotranspiration of the plantations exceeding regional rainfall (He et al., 2003; Li et al., 2008). The significant correlations between $P$ / PET ratio with model residuals in $0-20$ and $0-$ $40 \mathrm{~cm}$ soil depths suggested that soil water availability was an important factor for SOC sequestration in the upper $40 \mathrm{~cm}$ soil. The drop-off points of SOC measurements at older ages at the drier sites may be partially accounted for by the decreased ecosystem productivity due to water limitation (Eamus, 2003). In depth exploration of SOC changes with soil water dynamics and model validation will need longer-term in situ soil carbon monitoring and soil water measurements in further studies.

\subsection{Uncertainties of the study}

The major uncertainties of the study include four aspects. First, the use of SOC in croplands measured in recent years (2009 or 2010) as the initial soil carbon stock may have caused errors because it could have changed since the time of sampling compared to that of 1980 (Yu et al., 2012). Second, the litter input estimates and turnover rates are another source of uncertainties of the modeling. The variations in tree DBH and turnover rates of varied biomass components were considered in the calculation of confidence limits of the model by including the standard deviations of the input parameters. However, some uncertainties are rooted in the biomass allocation models as well as the assumption of linear correlation 
between annual litter input and stand age. Third, some uncertainties come from the chronosequence method since the stand conditions, such as landform and soil properties, could not be identical in reality (Cao et al., 2007; Foereid et al., 2011). Lastly, the sample sizes of measurements for the soil property parameters and fine root biomass were relatively small at some sites, which suggest uncertainties for predictions of annual fine root biomass and the results of residual analyses.

\section{Long-term sustainability of the plantations}

The role of afforestation in carbon sequestration has been increasingly studied in recent years. After the primary focus on the short-term benefits from the plantations, the long-term effects and sustainability have started to cause more concern (Foote and Grogan, 2010; Novara et al., 2011). The plantations of black locust are effective in improving SOC and soil quality after 10-20 yr of growth, a conclusion supported by this and some other studies (Matos et al., 2012). However, this species is a pioneer species in forest succession and has a relatively short life span. Specifically, sprouting and seedling are rarely successful, and the soil seedbank is lacking in late-successional species, fostering only perennial herbs due to the long-term and large-scale cultivation in the study region (Wang and Ren, 2004). Therefore, the longterm carbon sequestration capability of the plantations and their further recovery to natural vegetation communities are indispensable for suitable stand management, including timber harvesting, seedling supplementation and seed source introduction (Zhang et al., 2008). In addition, the growth of the plantations could be limited by soil water shortage especially at older stands of the drier sites, as mentioned earlier. Longer-term studies are needed to evaluate the sustainability of the plantations and their carbon sequestration capability in this area (Cao et al., 2010). Future afforestation activities should consider climate, site conditions, species adaptability, and successional stage at the same time.

\section{Supplementary material related to this article is available online at http://www.biogeosciences.net/10/ 7053/2013/bg-10-7053-2013-supplement.pdf.}

Acknowledgements. This study is financially supported by the National Natural Science Foundation of China (No. 41230745), the National Basic Research Program of China (No. 2009CB421104), the Cooperation Program of the Chinese Academy of Sciences (No. GJHZ1215), and the Academy of Finland (No. 256231).

Edited by: Z. Jia

\section{References}

Adamopoulos, S., Voulgaridis, E., and Passialis, C.: Variation of certain chemical properties within the stemwood of black locust (Robinia pseudoacacia L.), Eur. J. Wood Prod., 63, 327-333, 2005.

Adams, M., Crawford, J., Field, D., Henakaarchchi, H., Jenkins, M., McBratney, A., de Remy de Courcelles, V., Singh, K., Stockmann, U., and Wheeler, J.: Managing the soil-plant system to mitigate atmospheric $\mathrm{CO}_{2}$. Discussion paper for the Soil Carbon Sequestration Summit, 31 January-2 February 2011. The United States Studies Centre at the University of Sydney, 2011.

Breña Naranjo, J. A., Weiler, M., and Stahl, K.: Sensitivity of a data-driven soil water balance model to estimate summer evapotranspiration along a forest chronosequence, Hydrol. Earth Syst. Sci., 15, 3461-3473, doi:10.5194/hess-15-3461-2011, 2011.

Cao, S. X., Chen, L., and Liu, Z. D.: Impact of three soil types on afforestation in China's Loess Plateau, Landscape Urban Plan., 83, 208-217, 2007.

Cao, S. X., Wang, G. S., and Chen, L.: Questionable value of planting thirsty trees in dry regions, Nature, 465, 7294, doi:10.1038/465031d ,2010.

Chang, R. Y., Fu, B. J., Liu, G. H., Wang, S., and Yao, X. L.: The effects of afforestation on soil organic and inorganic carbon: A case study of the Loess Plateau of China, Catena, 95, 145-152, 2012a.

Chang, R. Y., Fu, B. J., Liu, G. H., Yao, X. L., and Wang, S.: Effects of soil physicochemical properties and stand age on fine root biomass and vertical distribution of plantation forests in the Loess Plateau of China, Ecol. Res. 27, 827-836, doi:10.1007/s11284-012-0958-0, 2012b.

Chapin, F. S. III, McFarland, J., McGuire, A. D., Euskirchen, E. S., Ruess, R. W., and Kielland, K.: The changing global carbon cycle: linking plant-soil carbon dynamics to global consequences, J. Ecol., 97, 840-850, 2009.

Davidson, E. A. and Janssens, I. A.: Temperature sensitivity of soil carbon decomposition and feedbacks to climate change, Nature, 440, 165-73, 2006.

Davis, M., Nordmeyer, A., Henley, D., and Watt, M.: Ecosystem carbon accretion 10 years after afforestation of depleted subhumid grassland plants with three densities of Pinus nigra, Glob. Change Bio., 13, 1414-1422, doi:10.1111/j.13652486.2007.01372.x, 2007.

Eamus, D.: How does ecosystem water balance affect net primary productivity of woody ecosystems?, Funct. Plant Bio., 30, 187205, 2003.

Fang, J. Y., Guo, Z. D., Piao, S. L., and Chen, A. P.: Terrestrial vegetation carbon sinks in China, 1981-2000, Sci. CHINA Ser. D., 50, 1341-1350, 2007.

FAO report: Carbon sequestration in dryland soils, World Soils Resources Reports 102, Natural Resources Management and Environment Department, Food and Agriculture Organization of the United Nations, Rome 2004, 2004.

Foereid, B., Lehmann, J., and Major, J.: Modeling black carbon degradation and movement in soil, Plant Soil, 345, 223-236, 2011.

Foote, R. and Grogan, P.: Soil carbon accumulation during temperate forest succession on abandoned low productivity agricultural lands, Ecosystems, 13, 795-812, 2010. 
$\mathrm{Fu}$, B. J.: Soil erosion and its control in the loess plateau of China, Soil Use Manage., 5, 76-82, 1989.

Fu, X. L., Shao, M. A., Wei, X. R., and Horton, R.: Soil organic carbon and total nitrogen as affected by vegetation types in Northern Loess Plateau of China, Geoderma, 155, 31-35, 2010.

Fu, B. J., Liu, Y., Lü, Y. H., He, C. S., Zeng, Y., and Wu, B. F.: Assessing the soil erosion control service of ecosystems change in the Loess Plateau of China, Ecol. Complex., 8, 284-293, 2011.

Geesing, D., Felker, P., and Bingham, R. L.: Influence of mesquite, Prosopis glandulosa. on soil nitrogen and carbon development: Implications for global carbon sequestration, J. Arid Environ., 46, 157-180, 2000.

Guo, L. B. and Gifford, R. M.: Soil carbon stocks and land use change, Global Change Bio., 8, 345-360, 2002.

Häkkinen, M., Heikkinen, J., and Mäkipää, R.: Soil carbon stock increases in the organic layer of boreal middle-aged stands, Biogeosciences, 8, 1279-1289, doi:10.5194/bg-8-1279-2011, 2011.

Han, F. P., Hu, W., Zheng, J. Y., Du, F., and Zhang, X. C.: Estimating soil organic carbon storage and distribution in a catchment of Loess Plateau, China, Geoderma, 154, 261-266, 2010.

He, X., Li, Z., Hao, M., Tang, K., and Zheng, F.: Down-scale analysis for water scarcity in response to soil-water conservation on Loess Plateau of China, Agr. Ecosyst. Environ., 94, 355-361, 2003.

Jandl, R., Lindner, M., Vesterdal, L., Bauwens, B., Baritz, R., Hagedorn, F., Johnson, D. W., Minkkinen, K., and Byrne, K. A.: How strongly can forest management influence soil carbon sequestration?, Geoderma, 137, 253-268, 2007.

Jensen, L. S., Salo, Y., Palmason, F., Breland, T. A., Henriksen, T. M., Stenberg, B., Pedersen, A., Lundstro, C., and Esala, M.: Influence of biochemical quality on $\mathrm{C}$ and $\mathrm{N}$ mineralisation from a broad variety of plant materials in soil, Plant Soil, 273, 307-326, doi:10.1007/s11104-004-8128-y, 2005.

Karhu, K., Wall, A., Vanhala, P., Liski, J., Esala, M., and Regina, K.: Effects of afforestation and deforestation on boreal soil carbon stocks - Comparison of measured C stocks with Yasso07 model results, Geoderma, 164, 33-45, 2011.

Laganiere, J., Angers, D. A., and Pare, D.: Carbon accumulation in agricultural soils after afforestation: a meta-analysis, Glob. Change Bio., 16, 439-453, 2010.

Li, D., Niu, S., and Luo, Y.: Global patterns of the dynamics of soil carbon and nitrogen stocks following afforestation: a metaanalysis, New Phytol., 195, 172-181 2012.

Li, J., Chen, B., Li, X., Zhao, Y., Ciren, Y., Jiang, B., Hu, W., Chen, J., and Shao, M.: Effects of deep soil desiccation on artificial forestlands in different vegetation zones on the Loess Plateau of China, Acta Ecol. Sin., 28, 1429-1445, 2008.

Liski, J., Palosuo, T., Peltoniemi, M., and Sievänen, R.: Carbon and decomposition model Yasso for forest soils, Ecol. Model., 189, 168-182, 2005.

Liski, J., Lehtonen, A., Palosuo, T., Peltoniemi, M., Eggers, T., Muukkonen, P., and Makipaa, R.: Carbon accumulation in Finland's forests 1922-2004 - an estimate obtained by combination of forest inventory data with modelling of biomass, litter and soil, Ann. Forest Sci., 63, 687-697, 2006.

Liu, Z. P., Shao, M. A., and Wang, Y. Q.: Large-scale spatial variability and distribution of soil organic carbon across the entire Loess Plateau, China, Soil Res., 50, 114-124, 2012.
Mäkipää, R., Liski, J., Guendehou, S., Malimbwi, R., and Kaaya, A.: Soil carbon monitoring using surveys and modeling General description and application in the United Republic of Tanzania, FAO forestry paper No. 168, 2012.

Matos, E. S., Freese, D., Bohm, C., Quinkenstein, A., and Huttl, R.: Organic matter dynamics in reclaimed lignite mine Soils under Robinia pseudoacacia L. plantations of different ages in Germany, Commun. Soil Sci. Plan., 43, 745-755, 2012.

Novara, A., Gristina, L., La Mantia, T., and Rühl, J.: Soil carbon dynamics during secondary succession in a semi-arid Mediterranean environment, Biogeosciences , 8, 11107-11138, doi:10.5194/bgd-8-11107-2011, 2011.

Oelbermann, M. and Voroney, R. P.: An evaluation of the Century model to predict soil organic carbon: examples from Costa Rica and Canada, Agroforest. Syst., 82, 37-50, 2011.

Paul, K. I., Polglase, P. J., Nyakuengama, J. G., and Khanna, P. K.: Change in soil carbon following afforestation, Forest Ecol. Manage., 168, 241-257, 2002.

Peltoniemi, M., Mäkipää, R., Liski, J., and Tamminen, P.: Changes in soil carbon with stand age-an evaluation of a modelling method with empirical data, Glob. Change Bio., 10, 2078-2091, 2004.

Peltoniemi, M., Thürig, E., Ogle, S., Palosuo, T., Schrumpf, M., Wutzler, T., Butterbach-Bahl, K., Chertov, O., Komarov, A., Mikhailov, A., Gärdenäs, A., Perry, C., Liski, J., Smith, P., and Mäkipää, R.: Models in country scale carbon accounting of forest soils, Silva Fenn., 41, 575-602, 2007.

Poeplau, C., Don, A., Vesterdal, L., Leifeld, J., Van Wesemael, B., Schumacher, J., and Gensior, A.: Temporal dynamics of soil organic carbon after land-use change in the temperate zone- carbon response functions as a model approach, Glob. Change Bio., 17, 2415-2427, doi:10.1111/j.1365-2486.2011.02408.x, 2011.

Rantakari, M., Lehtonen, A., Linkosalo, T., Tuomi, M., Tamminen, T., Heikkinen, J., Liski, J., Makipaa, R., Ilvesniemi, H., and Sievanen, R.: The Yasso07 soil carbon model-Testing against repeated soil carbon inventory, Forest Ecol. Manage., 286, 137147, 2012.

Shi, H. and Shao, M. A.: Soil and water loss from the Loess Plateau in China, J. Arid Environ., 45, 9-20, 2000.

Smal, H. and Olszewska, M.: The effect of afforestation with Scots pine (Pinus silvestris L.) of sandy post-arable soils on their selected properties. II. Reaction, carbon, nitrogen and phosphorus, Plant Soil, 305, 171-187, 2008.

Thum, T., Raisanen, P., Sevanto, S., Tuomi, M., Reick, C., Vesala, T., Raddatz, T., Aalto, T., Järvinen, H., Altimir, N., Pilegaard, K., Nagy, Z., Rambal, S., and Liski, J.: Soil carbon model alternatives for ECHAM5/JSBACH climate model, Evaluation and impacts on global carbon cycle estimates, J. Geophy. Res., 116, G02028, doi:10.1029/2010JG001612, 2011.

Tian, Q. F., Du, L. H., and Li, X. J.: Study on Biomass of Robinia pseudoacacia Plantation in the Beijing Xishan National Forest Park, J. Beijing Forest. Univ., 19, 104-107, 1997.

Torn, M. S., Trumbore, S. E., Chadwick, O. A., Vitousek, P. M., and Hendricks, D. M.: Mineral control of soil organic carbon storage and turnover, Nature, 389, 170-173, 1997.

Tuomi, M., Rasinmäki, J., Repo, A., Vanhala, P., and Liski, J.: Soil carbon model Yasso07 graphical user interface, Environ. Modell. Softw., 26, 1358-1362, 2011. 
Wang, H. and Ren, J. Z.: Seed bank of main forest types in Ziwu Mountains, J. Arid Land Resources Environ., 18, 130-136, 2004.

Wang, C. Y., Zhou, J. B., Wang, X., and Xia, Z. M.: Contents and Biodegradation of Soluble Organic Carbon in Different Plant Residues from the Loess Plateau, Environ. Sci., 32, 1139-1145, 2011.

Wiesmeier, M., Sporlein, P., Geu, U., Hangen, E., Haug, S., Reischl, A., Schilling, B., von Lutzow, M., and Kogel-Knabner, I.: Soil organic carbon stocks in southeast Germany, Bavaria. as affected by land use, soil type and sampling depth, Glob. Change Bio., 18, 2233-2245, doi:10.1111/j.1365-2486.2012.02699.x, 2012.

Yu, Y. Q., Huang, Y., and Zhang, W.: Modeling soil organic carbon change in croplands of China, 1980-2009, Global Planet Change, 82, 115-128, 2012.
Zhai, M. P., Jiang, S. N., and Jia, L. M.: Fine-root dynamics in mixed plantation of poplar and black locust, J. Beijing Forest. Univ., 24, 39-44, 2002.

Zhang, C. H., Zheng, Y. Q., Liu, N., Zong, Y. C., Jiao, M., and Guo, H. L.: Invasion of Robinia pseudoacacia and impacts on native vegetation, J. Beijing Forest. Univ., 30, 18-23, 2008.

Zou, H. Y., Liu, G. B., and Wang, H. S.: The vegetation development in North Ziwuling forest region in last fifty years, Acta Bot Boreal-Occident. Sin., 22, 1-8, 2002. 